\title{
Post-concussional symptoms, financial compensation and outcome of severe blunt head injury
}

\author{
WW MCKINLAY, DN BROOKS, MR BOND \\ From the Department of Psychological Medicine, University of Glasgow, Glasgow, Scotland
}

SUMMARY Two groups, each of 21 cases of severe blunt head injury, were compared. Patients in one group were pursuing claims for financial compensation while patients in the other were not. Patients were assessed on cognitive tests, and both patients and relatives were interviewed at 3,6 and 12 months after injury. There were few differences between claimants and non-claimants: post-concussional symptoms were common in both, cognitive performance was equal, and the reports given by relatives of changes in the patients were very similar. However, the reports given by patients themselves differed with claimants reporting slightly more symptoms than nonclaimants.

It is generally agreed that severe blunt head injury may result in significant distress for both the injured and their families. A variety of cognitive deficits have been demonstrated particularly in memory and concentration and generally in the more fluid, less highly practised abilities. ${ }^{1-5}$ The subjective, emotional and behavioural changes which may occur in the patient following injury have also been described, as have the effects of these "psychosocial" changes on family life. ${ }^{6-11}$ However, the extent to which these sequelae are related to the nature and the severity of the original injury and the extent to which they are secondary has been less thoroughly explored. Secondary factors may include individual differences in reaction to disability, the availability of social support, and whether or not financial compensation is being claimed. The last mentioned will be considered in this paper, along with the related issue of post-concussional symptoms.

The literature on the role of financial compensation following severe head injury is sparse, but where it has been discussed it has usually been in the context of drawing a distinction between the mildly injured and the severely injured. In the mildly head-injured, a post-concussional syndrome of headache, dizziness, poor concentration and mem-

Address for reprint requests: Mr WW McKinlay, University of Glasgow, Department of Psychological Medicine, 6 Whittingehame Gardens, Glasgow G12 0AA, Scotland.

Received 15 June 1983 Accepted 20 June 1983 ory, fatigue and irritability has often been attributed to psychological rather than organic factors. ${ }^{12} \mathrm{How}-$ ever, in a recent review of the evidence, Jennett and Teasdale draw the conclusion that "even brief concussion usually entails some structural damage to the brain" (ref 12, p 259) and that "the damage done by and the symptoms subsequently suffered after mild head injuries are frequently underestimated" (ibid p 263). In particular they noted that neuro-otological and psychological examinations have revealed a high incidence of abnormalities in mildly injured patients who show no abnormal signs on routine clinical neurological examination. Recent work on evoked potentials ${ }^{13}$ represents another promising route to exploring this area.

While research of this sort suggests that there may be an organic component underlying postconcussional symptoms, the desire for financial compensation has also been suspected of playing a part. Cook ${ }^{14}$ compared two groups of mildly injured cases (mean post-traumatic amnesia less than 30 minutes) and found claimants had more persistent post-concussional symptoms and longer absence from work than non-claimants. However, the fact that these conclusions were based on a response of less than $50 \%$ to a postal questionnaire detracts from their value. Cartlidge ${ }^{15}$ studied a group of predominantly mildly injured patients and found that those who had an increasing incidence of symptoms as time progressed were more likely to be claiming compensation than those with subsiding symptoms. Cartlidge and Shaw ${ }^{16}$ reporting on the same group of cases, noted that the patients with anxiety and 
depression were more likely to be claiming compensation than those in whom these symptoms were absent.

Miller has argued strongly for a link between claims for financial compensation and symptoms in the mildly head injured. The post-concussional syndrome is "graven on the heart of every claimant for compensation" following mild injury and symptoms nearly always remit on settlement of their claim"win or lose". ${ }^{17}$ Such cases are sharply contrasted with the severely brain-injured where postconcussional symptoms "are conspicuously absent" ${ }^{18}$ this absence in the more severely injured cases seems to suggest a non-organic aetiology in the mildly injured. However, Miller's conclusions must be set against a good deal of evidence to the contrary. Merskey and Woodforde ${ }^{19}$ found that the prospect of financial gain did not account for the clinical picture in their group of mild injuries, and Kelly $^{20}$ has shown that many claimants make good recoveries before settlement while many nonclaimants develop post-concussional symptoms. Moreover, Rimel et al $^{21}$ found high rates of morbidity and absence from work in their sample of patients 3 months after minor head injury, despite an absence of clinical signs, and this finding was not attributable to litigation. The disagreement between Miller's conclusions and others' findings may reflect the fact that Miller's sample was grossly atypical of the head injured population as a whole, consisting wholly of medico-legal referrals. ${ }^{22}$ As Cartlidge and Shaw note:- "... in the context of medico-legal examination (symptoms) are apt to be attributed to attempted deception for the basest of motives, yet how often are they encountered in everyday practice where 'functional overlay' is readily accepted on the basis of anxiety or diminished expectation of performance" (ref 16, p 153). In short, there is some controversy over the aetiology of post-concussional symptoms following mild head injury. The current view seems to be that the role of an organic component may have been underestimated in the past, but that psychological factors including compensation may play some part. There has been less comment in the literature on the link between compensation and symptoms in more severely injured cases. Not only is it evident that there is genuine organic impairment in such cases, but post-concussional symptoms have been thought by some authors to be relatively rare. Miller suggested that post-concussional symptoms are "conspicuously absent" in severe cases and that there is an inverse relationship between the likelihood of accident neurosis and severity of injury. ${ }^{17} 18$

The aim of the present paper is to examine the incidence of post-concussional symptoms and the effects, if any, that claiming compensation has on cognitive and psychosocial recovery during the first year following severe head injury. This is an issue of particular interest to both medical practitioners and clinical psychologists since they are often asked by lawyers to assess the extent of the mental and behavioural disturbance in patients following head injury and also to assess the extent to which such changes are directly attributable to the injury. Group comparison data will be reported to assess the overall significance of compensation in elevating complaints in the severely head injured in the year following injury. This group comparison is based on data collected in the course of a wider study of the psychological and social consequences of severe head injury some reports of which have already been published. ${ }^{4}{ }^{1011}$

\section{Method}

\section{Patients}

Two groups were drawn, by the method described below, from a larger group of 55 patients who, together with their relatives, were the subject of a wide ranging study into the psychological and social consequences of severe blunt head injury. Patients aged between 16 and 60 years were admitted to the study. "Severe" injury was defined by at least 2 days post-traumatic amnesia (PTA) assessed retrospectively and "blunt" injury was taken to include depressed fractures but to exclude penetrating localised wounds (for example, gunshot). Patients known to have pre-existing neurological impairments were excluded. All patients had passed through the neurosurgical unit at the Institute of Neurological Sciences (INS) in Glasgow, which is a secondary facility serving the West of Scotland to which head injured patients are transferred for investigations and treatments not available at primary receiving hospitals.

From the sample of 55 cases obtained in this way two groups, each of 21 cases, were selected. The first group consisted of all those cases in whom a claim for financial compensation was being pursued and which remained outstanding throughout the 12 months of the follow-up. The second group consisted of all those cases in which no such claim was being pursued. In the remaining 13 cases, there was doubt as to whether they had grounds or sufficient evidence to pursue a claim. A description of the demographic and clinical characteristics of the two groups studied is provided in tables $1-5$, which indicate inter alia that the sample was on the whole very severely injured. More non-claimants had a neurosurgical operation, reflecting differences between groups in the number of haematomas. Previous research 5 has indicated that better cognitive outcome was associated with operated haematomas but this was attributable to shorter PTA in the operated group. In the present study non-claimants tended to have shorter PTA but not to a statistically significant extent $(p>0.05)$. Sex and social class distributions were very similar for each group as was the relationship of relatives interviewed to patients. However, claimants were significantly younger than non-claimants 
Table 1 Nature of injury

\begin{tabular}{lcc}
\hline & Claim & No Claim \\
\hline Location or cause: & 10 & 6 \\
Road traffic accident & 5 & 0 \\
Accident at work & 6 & 3 \\
Assault & 0 & 12 \\
Other & 21 & 21 \\
& & \\
Major complications: & 7 & 3 \\
Skull fracture only & 4 & 3 \\
Haematoma only & 4 & 12 \\
Both & 6 & 3 \\
Neither & -21 & 21 \\
& 21 & \\
Neurosurgical operation: & 7 & 15 \\
Yes & 14 & 6 \\
No & 21 & 21 \\
\hline
\end{tabular}

Table 2 Duration of post-traumatic amnesia (PTA)

\begin{tabular}{ccc}
\hline & Claim & No Claim \\
\hline $2-7$ days & 5 & 4 \\
$8-14$ days & 2 & 4 \\
$15-30$ days & 4 & 7 \\
$31-60$ days & 3 & 5 \\
$61-90$ days & 2 & 1 \\
Over 90 days & $\frac{3}{19 *}$ & $\frac{0}{21}$ \\
& $19^{*}$ & 21 \\
\hline
\end{tabular}

Median PTA is 29.7 days for the claim group and 20.7 days for the no claim group.

*In 2 of the 21 cases in this group, no reliable estimate of PTA could be obtained.

Table 3 Age, sex and marital status

\begin{tabular}{|c|c|c|}
\hline & Claim & No Claim \\
\hline \multirow{5}{*}{$\begin{array}{l}\text { Age at injury (mean, SD) } \\
\text { Sex (males, females) } \\
\text { Marital status: } \\
\text { Married/cohabiting } \\
\text { Separated/divorced/ } \\
\text { widowed } \\
\text { Single }\end{array}$} & $\begin{array}{l}31 \cdot 2,12 \cdot 7 \\
18,3\end{array}$ & $\begin{array}{l}43 \cdot 2,12 \cdot 5 \\
18,3\end{array}$ \\
\hline & & \\
\hline & 12 & 16 \\
\hline & 2 & $\begin{array}{l}0 \\
5\end{array}$ \\
\hline & 21 & 21 \\
\hline
\end{tabular}

Table 4 Social class distribution: number of patients in each of the Registrar-General's social classes

\begin{tabular}{lllllrl}
\hline & \multicolumn{3}{l}{ Social class } & & Total \\
\cline { 2 - 6 } & 1 & 2 & 3 & 4 & 5 & \\
\hline Claim & 0 & 3 & 7 & 6 & 5 & 21 \\
No claim & 1 & 2 & 4 & 4 & 10 & 21 \\
\hline
\end{tabular}

Table 5 Relationship of informants to patients

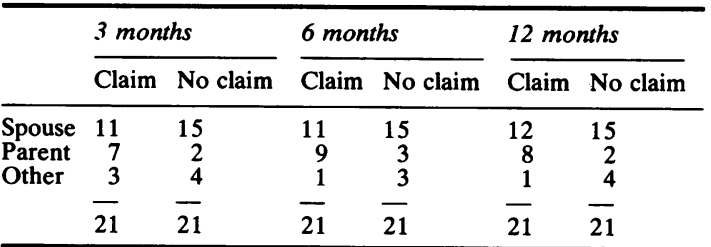

Note: All informants were involved in day-to-day contact with the patients, and where possible the same informant was interviewed at each follow-up.

( $p<0.01)$ and this difference will be considered in the group comparisons to be reported.

Procedure

Assessments were carried out at 3, 6 and 12 months after injury using a battery of psychometric measures and a brief structured interview asking patients about symptoms which they had noticed since injury. Relatives were also interviewed separately from the patients on each occasion and were asked to report changes in the patient which emerged after injury. All relatives interviewed bore a major dayto-day responsibility for care of the patient.

\section{Results}

\section{Psychometric test scores}

Claimants and non-claimants were compared on psychometric test performance on a range of tests: these were tests of Verbal IQ (Mill Hill Vocabulary $\mathrm{Scale}^{23}$ ), Non-verbal IQ (Raven's Progressive Matrices $^{24}$ ), immediate and delayed verbal recall (Logical Memory Sub-Test from the Wechsler Memory $\mathrm{Scale}^{25}$ ), immediate and delayed visual recall (Rey Picture Test $^{26}$ ), receptive language (number correct on Part 5 of the Token Test ${ }^{27}$ ) and expressive language (Word Fluency Test ${ }^{28}$ ). A series of two-tailed $t$ tests was carried out to determine if there were any differences between claimants and non-claimants. Eight of the 24 comparisons generated in this way were significant $(p<0.05)$ and all of these indicated that the claimants had performed better on the tests than non-claimants. However, there was a statistically significant $(p<0.01)$ tendency for the claimants to be younger and since this clearly might have an influence on test scores a series of analyses of co-variance was carried out using age as co-variate. When this was done, all but two of the significant differences disappeared leaving only two differences which were significant at the $5 \%$ level. With only two out of 24 comparisons reaching the $5 \%$ level of significance, it may be concluded that there was no overall difference in psychometric test performance between claimants and non-claimants. 
2. Relatives' reports of patients' syndromes

A series of analyses was carried out on the information given by relatives about changes in the patients. On the basis of the structured interviews which had been carried out with relatives at each follow-up, we calculated the mean number of changes which the relatives reported in each of seven areas of functioning. This number was scaled as if "out of 10 " so that the number of changes reported in each area would be comparable, and the results are summarised in the figure. In both claim and no claim groups emotional and subjective changes were most frequently reported and the profiles of the claim and no-claim groups were very similar indeed. Claim and noclaim groups were compared statistically on each of the seven areas of functioning at each of the three follow-ups. $T$ tests indicated that none of the 21 comparisons reached the $5 \%$ level of significance (two-tailed). These results fail to provide support for the proposition that the relatives of claimants report more extensive changes in the patients than do relatives of non-claimants. In order to exclude the possibility of a specific difference in respect of post-concussional symptoms, a further analysis was carried out. The numbers of post-concussional

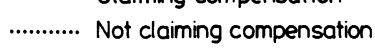

3 months after injury

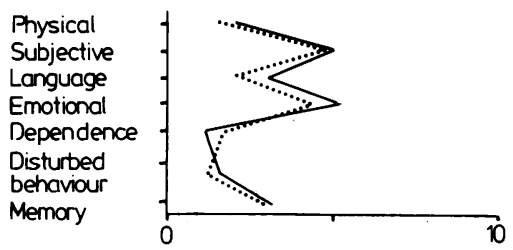

6 months after injury

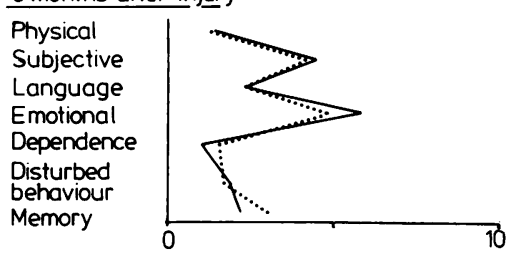

12 months after injury

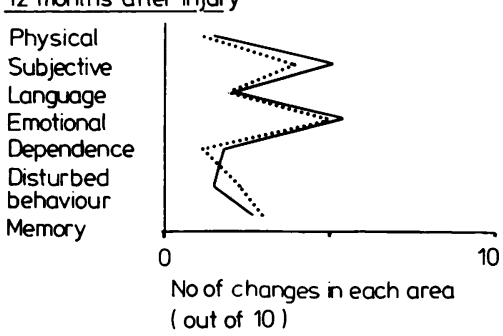

Fig Mean changes in patients as reported by relatives. symptoms present in claim and no-claim groups were compared using the group of four core postconcussional symptoms suggested by Miller, ${ }^{17}$ that is, headaches, dizziness, irritability and poor concentration (table 6). At each follow-up, comparison by Mann-Whitney $U$ test revealed no statistically significant difference.

\section{Patients' reports of their symptoms}

The next series of analyses carried out was on the patients' own responses to the structured interview mentioned above. Firstly, three of the four core post-concussional symptoms were examined (poor concentration, dizziness and irritability). A question about headache had not been included in the patients' structured interview because we had accepted the view-which we now believe to be mistaken-that post-concussional symptoms are rare after severe head injury. The number of these post-concussional symptoms reported by the patients in each group is given in table 7. Claimants tended to report more symptoms than nonclaimants, this difference reaching statistical significance on the Mann-Whitney U test $(p<0.05)$ at 3 and 12 months follow-up. Next, the total number of symptoms reported by patients from a widerranging list of 20 items was calculated. The claim and no-claim groups were compared (table 8). $T$ tests indicated that there was a significant difference at each follow-up. When the effects of age and PTA were co-varied out the difference remained significant at the $5 \%$ level at all three follow-up times indicating an overall tendency for patients who were claiming compensation to report more symptoms than those who were not claiming.

\section{Return to work}

The numbers of claimants and non-claimants who had returned to work at each follow-up were compared. Only patients who had returned to work or those who had not done so only because they were "unfit for work" were included: patients who were unemployed for reasons unrelated to injury were excluded as were the retired, students and housewives. These data are summarised in table 9. No statistically significant association between claiming compensation and return to work was found at any follow-up using Fisher's exact test or the Chi-square test as appropriate $(p>0.05)$.

\section{Post-concussional symptoms}

A substantial number of these severely injured patients experienced some post-concussional symptoms according to the reports both of the patients themselves and their relatives (tables 6 and 7). As a 
Table 6 Number of patients with "post-concussional" symptoms (headache, dizziness, irritability, poor concentration) as reported by relatives as a function of compensation claim.

\begin{tabular}{llllllll}
\hline & & \multicolumn{4}{c}{ Number of symptoms } & \multirow{2}{*}{$N$} \\
\cline { 2 - 6 } & & 0 & 1 & 2 & 3 & 4 & \\
\hline \multirow{2}{*}{3 months after injury } & Claim & 2 & 7 & 5 & 3 & 3 & 20 \\
& No Claim & 3 & 5 & 5 & 4 & 1 & 18 \\
6 months after injury & Claim & 3 & 5 & 6 & 4 & 2 & 20 \\
& No Claim & 4 & 5 & 4 & 6 & 1 & 20 \\
12 months after injury & Claim & 3 & 4 & 5 & 7 & 2 & 21 \\
& No Claim & 5 & 3 & 6 & 5 & 1 & 20 \\
\hline
\end{tabular}

At each follow-up, comparison of claim and no claim groups by Mann-Whitney $U$ test (2-tailed) reveals no significant difference. $(p>0.05)$

Table 7 Number of patients reporting

"post-concussional" symptoms (poor concentration, dizziness, irritability) as a function of compensation claim

\begin{tabular}{|c|c|c|c|c|c|}
\hline & \multicolumn{4}{|c|}{ Number of symptoms } & \multirow[t]{2}{*}{$N$} \\
\hline & 0 & 1 & 2 & 3 & \\
\hline $\begin{array}{l}3 \text { months after injury } \quad \text { Claim } \\
\text { po (Mann-Whitney } U, 2 \text {-tailed })<0.0\end{array}$ & $\begin{array}{l}5 \\
10 \\
05\end{array}$ & $\begin{array}{l}4 \\
7\end{array}$ & $\begin{array}{l}5 \\
1\end{array}$ & $\begin{array}{l}3 \\
0\end{array}$ & $\begin{array}{l}17 \\
18\end{array}$ \\
\hline $\begin{array}{l}6 \text { months after injury } \quad \text { Claim } \\
\text { No Claim } \\
\text { (Mann-Whitney U, 2-tailed) }>0.0\end{array}$ & $\begin{array}{l}5 \\
11 \\
05\end{array}$ & $\begin{array}{l}7 \\
3\end{array}$ & $\begin{array}{l}5 \\
5\end{array}$ & $\begin{array}{l}3 \\
1\end{array}$ & $\begin{array}{l}20 \\
20\end{array}$ \\
\hline $\begin{array}{l}12 \text { months after injury } \quad \text { Claim } \\
\mathrm{p} \text { (Mann-Whitney } \mathrm{U}, 2 \text {-tailed) }<0 \cdot 0\end{array}$ & $\begin{array}{r}3 \\
9 \\
05\end{array}$ & $\begin{array}{l}8 \\
7\end{array}$ & $\begin{array}{l}8 \\
5\end{array}$ & $\begin{array}{l}2 \\
0\end{array}$ & $\begin{array}{l}21 \\
21\end{array}$ \\
\hline
\end{tabular}

Table 8 Total number of symptoms (out of 20) reported by patients as a function of compensation claim

\begin{tabular}{llll}
\hline & \multicolumn{3}{l}{ Time after injury } \\
\cline { 2 - 4 } & 3 months & 6 months & 12 months \\
\hline Claim & 6.2 & 6.5 & 7.3 \\
No Claim & 4.2 & 3.8 & 4.5 \\
$\begin{array}{l}\text { Significance of: } \\
\quad \text { test (2-tailed) }\end{array}$ & $\mathrm{p}<0.05$ & $\mathrm{p}<0.01$ & $\mathrm{p}<0.01$ \\
$\begin{array}{l}\text { ANCOVA with } \\
\text { Age and PTA } \\
\text { as covariates }\end{array}$ & $\mathrm{p}<0.05$ & $\mathrm{p}<0.05$ & $\mathrm{p}<0.05$ \\
\hline
\end{tabular}

Table 9 Return to work as a function of compensation claim

\begin{tabular}{lllll}
\hline & & Working & Not working & $N$ \\
\hline \multirow{2}{*}{ months after injury } & Claim & 1 & 11 & 12 \\
& No Claim & 3 & 12 & 15 \\
months after injury & Claim & 3 & 11 & 14 \\
12 months after injury & No Claim & 6 & 8 & 14 \\
& Claim & 9 & 6 & 15 \\
& No Claim & 6 & 6 & 12 \\
\hline
\end{tabular}

In each case, the Fisher exact test or the chi-square test, as appropriate, indicates no significant association $(p>0.05)$ between the variables.
Table 10 Number of patients reporting post-concussional symptoms as a function of compensation claim $(C=$ claim group, $N C=$ no-claim group $)$

\begin{tabular}{|c|c|c|c|c|c|c|}
\hline & \multicolumn{6}{|c|}{ Time after injury } \\
\hline & \multicolumn{2}{|c|}{3 months } & \multicolumn{2}{|c|}{6 months } & \multicolumn{2}{|c|}{12 months } \\
\hline & $C$ & $N C$ & $C$ & $N C$ & $C$ & $N C$ \\
\hline $\begin{array}{l}\text { Poor concentration } \\
\text { Depressed mood } \\
\text { Irritability } \\
\text { Fatigue }\end{array}$ & $\begin{array}{r}9 / \\
11 / \\
9 / \\
11 /\end{array}$ & $\begin{array}{l}75 / 19 \\
38 / 18 \\
75 / 18 \\
57 / 18\end{array}$ & $\begin{array}{l}8 / 20 \\
12 / 20 \\
13 / 20^{*} \\
14 / 20\end{array}$ & $\begin{array}{r}8 / 20 \\
7 / 20 \\
5 / 20 \\
10 / 20\end{array}$ & $\begin{array}{lr}0 & 8 / 21 \\
0 & 11 / 21 \\
0 & 15 / 21 \\
0 & 15 / 21\end{array}$ & $\begin{array}{l}2 / 21 \\
9 / 21 \\
9 / 21 \\
9 / 21\end{array}$ \\
\hline
\end{tabular}

Table 11 Number of patients suffering post-concussional symptoms according to relatives' reports as a function of compensation claim.

$(C=$ claim group, $N C=$ no-claim group $)$

\begin{tabular}{|c|c|c|c|c|c|c|}
\hline & \multicolumn{6}{|c|}{ Time after injury } \\
\hline & \multicolumn{2}{|c|}{3 months } & \multicolumn{2}{|c|}{6 months } & \multicolumn{2}{|c|}{12 months } \\
\hline & $C$ & $N C$ & $C$ & $N C$ & $C$ & $N C$ \\
\hline $\begin{array}{l}\text { Poor concentration } \\
\text { Depressed mood } \\
\text { Irritability } \\
\text { Fatigue } \\
\text { Headaches }\end{array}$ & $\begin{array}{l}11 / 21 \\
14 / 20 \\
12 / 21 \\
18 / 20 \\
12 / 20\end{array}$ & $\begin{array}{r}6 / 20 \\
11 / 21 \\
13 / 21 \\
15 / 20 \\
12 / 21\end{array}$ & $\begin{array}{r}10 / 20 \\
14 / 21 \\
16 / 21 \\
12 / 20 \\
9 / 21\end{array}$ & $\begin{array}{r}7 / 21 \\
10 / 21 \\
13 / 21 \\
16 / 21 \\
12 / 20\end{array}$ & $\begin{array}{l}10 / 21 \\
13 / 20 \\
15 / 21 \\
15 / 21 \\
12 / 21\end{array}$ & $\begin{array}{r}5 / 20 \\
11 / 21 \\
13 / 21 \\
11 / 21 \\
10 / 21\end{array}$ \\
\hline
\end{tabular}

For all comparisons, $\mathrm{p}$ (Chi-square) $>0.05$.

further way of examining the prevalence of postconcussional symptoms, the number of patients experiencing particular symptoms was calculated. The symptoms were a selection of those identified as "post-concussional" in the literature. ${ }^{12} 1617$ The patients' own accounts are summarised in table 10. Here, similarly to the analyses reported in table 7 , there was a tendency for more claimants than nonclaimants to report symptoms: all differences were in this direction although only one out of $12 \mathrm{com}$ parisons reached the $5 \%$ level of significance on the Chi-square test. The relatives' reports of patients' symptoms are summarised in table 11 . Here there were no significant between group differences, which is consistent with the analyses already carried out on relatives' reports. In addition to these symptoms, between one third and one half of the relatives reported that the patients showed intolerance of noise and reduced tolerance of alcohol, and most reported poor memory and increased anxiety. In short, relatives reported a wide range of postconcussional symptoms in both claimants and nonclaimants. 


\section{Discussion}

This study has found a high level of postconcussional symptoms in the severely head injured during the year following injury. This is in accord with the findings of Kelly, ${ }^{20}$ who also found such symptoms following severe injury. It is at odds with the view of Miller that post-concussional symptoms are rare and are "hardly ever volunteered in the histories of patients (with) severe cerebral trauma". ${ }^{17}$ However, failure to "volunteer" is not the same as absence: in the present study other symptoms and difficulties were more dramatic and evident but direct questioning uncovered postconcussional symptoms. These symptoms did not occur in all-or-none fashion but were present in varying numbers. This supports the view of Cartlidge and $S_{h a w}{ }^{16}$ that there is not a well-defined postconcussional syndrome but rather a loosely associated collection of symptoms. Moreover, the presence of post-concussional symptoms in the severely injured, especially those not claiming financial compensation, leaves open the possibility of an organic basis which would be much less likely if these symptoms were largely confined to mildly injured claimants, as has been alleged. ${ }^{17}$

There were some differences between claimants and non-claimants in the present study, and these should be considered in the context of the overall group comparisons. On psychometric tests, the tendency of claimants to obtain higher scores than non-claimants was attributable to the tendency for claimants to be younger. When age was controlled statistically there was no consistent difference between groups. In short, it seems that claimants did not attempt to fake low scores in order to present as more disabled than they were. Of course, this does not mean that no one ever tries to fake low scores. However, the present authors believe from their own clinical experience that serial testing uncovers this easily in the very few cases where it occurs, and the present findings support the view that faking low scores is rare.

The accounts of changes in the patients given by relatives in the course of separate interviews were not influenced by whether or not financial compensation was being claimed. The profiles of changes in claiming and non-claiming patients, obtained from relatives, were very similar indeed (fig) with no significant differences at any stage. Both groups reported the same overall picture as that reported in the larger group of 55 cases from which they were drawn: ${ }^{10}$ emotional and subjective changes were considerably more common than other kinds of change. In addition, relatives' accounts of specific post-concussional symptoms in the patients did not differ between claimants and non-claimants. It seems, therefore, that relatives are good witnesses inasmuch as their accounts are not influenced by whether or not a claim for financial compensation is being made.

Unlike psychometric test scores and relatives' accounts, the patients' own accounts of their symptoms revealed consistent differences between claimants and non-claimants. Those who were claiming compensation tended to report more symptoms than those who were not claiming. While the differences may have been related to the differing age and severity of injury in the two groups, even when these two factors were statistically controlled, significant differences remained. Nor can it be argued that only those with poor outcomes considered it worth claiming: the key element in the decision to claim was culpability and the availability of witnesses.

The tendency for claimants to report more problems was slight vis-à-vis post concussional symptoms, reaching statistical significance in some analyses only (tables 7 and 10). However, this tendency became more robust when all 20 items in the symptom checklist were included (table 8) and appeared to be a general effect rather than one specific to particular symptoms. Nevertheless, the difference between groups was fairly modest in size and must be considered alongside our other findings. In particular, these patients did not fake low scores on psychometric tests and this study did not find evidence that claimants were absent from work for longer than non-claimants. Taken together, these findings do not support the conclusion that claimants make a widespread and concerted effort to present as more disabled than they are.

The findings of this study raise a number of issues. That different conclusions were reached on the basis of patients' and relatives' reports deserves comment. It has been noted that although agreement between patient and relative is usually quite high, relatives sometimes report changes in patients which the patients themselves fail to admit. This "lack of insight" seems to occur mainly over emotional and behavioural changes and is not generally a function of the patients' cognitive level. ${ }^{62930}$ Moreover, further evidence from our own research indicates that the personality of relatives may colour the accounts they give to a modest degree. ${ }^{30}$

Of more importance in the present context is the question of how we may account for the differences between the reports of patients who claimed compensation and those who did not. What factors underlie the deficits and symptoms observed after head injury? Firstly, it is beyond doubt that organic brain damage plays an important part both with regard to cognitive and other broader aspects of 
outcome..$^{531}$ It is also quite possible, as has already been argued, that post-concussional symptoms have an organic basis. Secondly, it is likely that a variety of psychological and social factors influence outcome: these may include premorbid personality and availability of social supports, although precise evidence about these remains lacking. In addition, Kelly $^{20}$ has argued that failure to be offered proper treatment may prolong post-concussional symptoms in claimants for compensation. Thirdly, there is no doubt that some patients malinger or simulate disability with a view to increasing a claim for financial compensation. Kelly argues that "The stupid, the greedy and the histrionic are always with us, but ... it is unreasonable to suppose that (because some) attempt a fraud on insurance companies, all patients who have suffered a head injury for whom a claim is outstanding and who have ... post-traumatic syndrome should therefore be labelled as fraudulent and refused treatment" (ref 20, p 24).

In the present study, it seems unlikely that organic factors could account for between group differences. There was no significant difference in PTA between groups, and in any event PTA was used as a covariate to control for the small difference which did exist. Nor were there differences in cognitive outcome which would have been expected if there were different levels of organic impairment. Malingering or simulation of disability also seem unlikely. Had this been present, one would have expected a greater difference between the reports of claimants and non-claimants together with some attempt to obtain low cognitive test scores. Relatives' accounts might also have differed between groups.

If neither organic factors nor malingering adequately account for the between group differences, can psychological factors do so? There is no reason to believe that there are systematic premorbid psychological differences between groups. However, Rutherford et al observed, in relation to mild injuries, that persisting symptoms may be related to blaming an employer or impersonal body for the injury, rather than oneself or another individual. ${ }^{32}$ Merskey and Woodforde, again discussing mild injury, pointed out that the uncertainty which attaches to the process of litigation may be harmful. ${ }^{19}$ And Kelly, as already noted, argued for an element of iatrogenesis. ${ }^{20}$ It may be that such considerations best account for the differences between claimants and non-claimants observed in the present study.

Finally, two practical implications for assessing compensation claimants are drawn from the study. Firstly, it is important to assess cognitive function and to conduct separate interviews with relatives to obtain views unbiased by compensation. A careful interview with the patient is also required if all significant symptoms are to be uncovered: postconcussional symptoms are often present in the severely injured even if less obvious than their other problems. Secondly, examination should be made in the knowledge that major exaggeration of disability is rare.

The investigation was supported by the Medical Research Council, Grant No. G/975/928.

We are grateful to the Consultant Neurosurgeons at the Institute of Neurological Sciences, Southern General Hospital, Glasgow, who allowed their patients to be studied.

\section{References}

${ }^{1}$ Mandelberg I, Brooks DN. Cognitive recovery after severe head injury. J Neurol Neurosurg Psychiatry 1975;38:1121-6.

${ }^{2}$ Schacter DL, Crovitz HF. Memory function after closed head injury: a review of the quantitative research. Cortex 1977;13:150-76.

${ }^{3}$ Zomeren AH van, Deelman BG. Long-term recovery of visual reaction time after closed head injury. $J$ Neurol Neurosurg Psychiatry 1978;41:452-7.

${ }^{4}$ Brooks DN, Aughton ME. Psychological consequences of blunt head injury. Int Rehab Med 1979;1:160-5.

${ }^{5}$ Brooks DN, Aughton ME, Bond MR, Jones P, Rizvi S. Cognitive sequelae in relationship to early indices of severity of brain damage after severe blunt head injury. J Neurol Neurosurg Psychiatry 1980;43:52934.

${ }^{6}$ Thomsen IV. The patient with severe head injury and his family. Scand J Rehab Med 1974;6:180-3.

${ }^{7}$ Rosenbaum M, Najenson T. Changes in life patterns and symptoms of low mood as reported by wives of severely brain injured soldiers. J Consult Clin Psychol 1976;44:881-8.

${ }^{8}$ Lezak MD. Living with the characterologically altered brain injured patient. J Clin Psychiatry 1978;39:592-8.

${ }^{9}$ Oddy M, Humphrey M, Uttley D. Stress upon the relatives of head-injured patients. $\mathrm{Br} J$ Psychiatry 1978;133:507-13.

${ }^{10}$ McKinlay WW, Brooks DN, Bond MR, Martinage DP, Marshall MM. The short term outcome of severe blunt head injury as reported by relatives of the injured persons. $J$ Neurol Neurosurg Psychiatry $1981 ; 44: 527-33$.

"Brooks DN, McKinlay WW. Personality and behavioural change after severe blunt head injury-a relative's view. J Neurol Neurosurg Psychiatry 1983;46:336-44.

12 Jennett B, Teasdale G. Management of Head Injuries. Philadelphia: FA Davis Company, 1981.

${ }^{13}$ Noseworthy JH, Miller J, Murray TJ, Regan D. Auditory brainstem responses in post concussion syndrome. Arch Neurol 1981;38:275-8. 
${ }^{14}$ Cook JB. The post-concussional syndrome and factors influencing recovery after minor head injury admitted to hospital. Scand J Rehab Med 1972;4:27-30.

${ }^{15}$ Cartlidge NEF. Post-concussional syndrome. Scot Med J 1978;23:103.

${ }^{16}$ Cartlidge NEF, Shaw DA. Head Injury. London: WB Saunders Co Ltd, 1981.

${ }^{17}$ Miller H. Mental after-effects of head injury. Proc $R$ Soc Med 1966;59:257-61.

${ }^{18}$ Miller H, Stern G. The long-term prognosis of severe head injury. Lancet 1965 ;i:225-9.

${ }^{19}$ Merskey H, Woodforde JM. Psychiatric sequelae of minor head injury. Brain 1972;95:521-8.

${ }^{20}$ Kelly R. The post-traumatic syndrome: an iatrogenic disease. Forensic Sci 1975;6:17-24.

${ }^{21}$ Rimel RW, Giordani B, Barth JT, Boll TJ, Jane JA. Disability caused by minor head injury. Neurosurgery 1981;9:221-8.

${ }^{22}$ Miller H. Accident neurosis. Br Med J 1961;i:919-25, 992-8.

${ }^{23}$ Raven JC. Extended guide to Mill Hill Vocabulary Scales. London: HK Lewis, 1962.

${ }^{24}$ Raven JC. Guide to the Standard Progressive Matrices.
London: HK Lewis, 1960.

${ }^{25}$ Wechsler D. A standardized memory scale for clinical use. J Psychol 1954;19:87-95.

${ }^{26}$ Rey A. L'examen psychologique dans les cas d'encephalopathie traumatique. Archives de Psychologie 1942;28:112.

${ }^{27}$ De Renzi E, Vignolo LA. The token test: a sensitive test to detect receptive disturbances in aphasics. Brain 1962;85:665-78.

${ }^{28}$ Borkowski JG, Benton AL, Spreen O. Word fluency and brain damage. Neuropsychologia 1967;5:135-40.

${ }^{29}$ Fany TJ, Irving MH, Millac P. Severe head injuries: a six-year follow-up. Lancet 1967;ii:475-9.

${ }^{30}$ McKinlay WW, Brooks DN. Methodological problems in assessing psychosocial recovery following severe head injury. J Clin Neuropsychology, 1983 in press.

${ }^{31}$ Jennet B, Snoek J, Bond MR, Brooks DN. Disability after severe head injury: observations on the use of the Glasgow Outcome Scale. J Neurol Neurosurg Psychiatry 1981;44;285-93.

${ }^{32}$ Rutherford WH, Merrett JD, McDonald JR. The sequelae of concussion caused by minor head injuries. Lancet 1977;i:1-4. 